\title{
EDITORIAL OPEN Drinking water quality and the SDGs
}

npj Clean Water (2020)3:37; https://doi.org/ $10.1038 / \mathrm{s} 41545-020-00085-z$

Access to safe drinking water is recognized as a human right and has long been a goal of national and international policy. The United Nations' Sustainable Development Goals (SDGs) include ambitious global targets for drinking water, sanitation and hygiene. The indicator for SDG target 6.1, use of safely managed drinking water services (SMDW), seeks to address the limitations of previous monitoring efforts ${ }^{1}$. SMDW services are defined as improved sources of drinking water (piped water, protected groundwater sources, rainwater collection and packaged or delivered water) that are accessible on premises, available when needed and free from contamination $^{2}$. For global reporting on drinking water quality the WHO/UNICEF Joint Monitoring Programme (JMP) for Water Supply, Sanitation and Hygiene focuses on the major priorities from a public health perspective: faecal contamination as indicated by detection of Escherichia coli, and elevated levels of arsenic and fluoride. While these three key parameters are the focus of SDG monitoring at global level, WHO's Guidelines for Drinking Water Quality ${ }^{3}$ provide the normative framework that underpins national standards in many countries and cover a far wider range of water quality parameters. The latest estimates from the JMP find that around 2 billion people lack SMDW, the majority in Central and South Asia (768 million) and Sub-Saharan Africa (747 million) and demonstrate that contamination of drinking water is often the limiting factor for $\mathrm{SMDW}^{4}$. Despite an increase from 96 to 117 countries with SMDW estimates between the 2017 and 2019 JMP reports, a large number of UN Member States are still unable to report on SMDW, often due to a lack of nationally-representative data on water quality.

The SDGs have provided the impetus for many countries to reflect on and to attempt to fill data gaps on drinking water quality. This collection of papers-a collaboration between the WHO/ UNICEF JMP and npj Clean Water-reviews emerging water quality data and explores exposure assessments, risk factors for contamination, health impacts, as well as new approaches for collecting data on water quality. The collection focuses on large-scale assessments of faecal contamination and global priority chemical contaminants such as arsenic and fluoride, and includes studies of other contaminants, or those focused on vulnerable populations. The collection includes examples of nationally-representative assessments of drinking water quality and safely managed services in Ecuador ${ }^{5}$ and the Democratic People's Republic of Korea (DPRK) ${ }^{6}$. These large-scale surveys demonstrate the importance of addressing faecal contamination of drinking water, the limiting factor for SMDW in both countries, and the potential for household surveys to become a major source of data on drinking water quality. National estimates of the proportion of the population using drinking water sources that are free from contamination were $74 \%$ in Ecuador and $77 \%$ in DPRK. The studies also enable the examination of risk factors associated with contamination and the populations most affected by contaminated drinking water-highlighting the poorest and those in rural areas as most likely to be affected. To date more than 30 countries have conducted water quality testing in household surveys ${ }^{7}$, in many cases generating representative data for the first time (Table 1). These surveys find large proportions of the population are exposed to faecal contamination through drinking water, and that there can be a substantial difference between the point of collection and point of use.

Smaller-scale water quality assessments covering a wider range of water quality parameters and other indicators related to drinking water services and their impacts are essential to provide a nuanced understanding of the risk factors for contamination for different settings and drinking water services, including those used by vulnerable populations. Three studies demonstrate the challenges of providing high-quality services in rapidly urbanizing sub-Saharan Africa, even for users of piped water systems. Jeandron et al. provide a compelling example of the use of spatial data on tap locations and invoices to predict water quality in household stored water in Ulvira, Democratic Republic of Congo $^{8}$. The authors rightly note the importance of identifying target areas for intervention in more localized spatial scales than afforded by national household surveys. Marks et al. explore water and sanitation services in Uganda in rural-urban transition zones, finding that piped water did not offer protection at the point of use and that over half of samples from storage containers contained detectable $E$. coli ${ }^{9}$. Similarly, Hubbard et al. investigated stored water quality in peri-urban Lusaka, where $75 \%$ of samples were contaminated which was associated with increased risk of diarrhoea and other illnesses ${ }^{10}$. In these contexts, and in many other parts of the world where supplies are intermittent and/or located off premises, households must store drinking water at home introducing additional opportunities for contamination to occur. The links between water service continuity and quality are well-established yet studies in this collection demonstrate that monitoring hours of service can be difficult ${ }^{11}$ and note the risks of considering water quality and quantity in isolation ${ }^{12}$. String et al. investigated methods for cleaning household storage containers but did not identify a practical method for removing biofilms ${ }^{13}$ illustrating the challenges these households face - and filling a gap in the biofilms literature which has largely focused on piped water systems. Naser et al. highlight specific concerns associated with the growing use of rainwater in Bangladesh which go beyond ensuring that it is free from contamination and consider the implications of mineral deficiencies for cardiovascular diseases ${ }^{14}$.

There is strong demand for simpler, faster, low-cost methods to enable more widespread and frequent testing by water service providers, regulators and potentially communities or individual households. A common objective-and focus of studies in this collection-is to reduce reliance on laboratory testing to avoid the complexity, cost and delays associated with sending samples offsite for testing, particularly in contexts where the nearest laboratory is far away or lacks reliable electricity. Brown et al. compare two new culture-based field testing approaches with a reference standard in Bangalore, India finding that these perform favourably when incubated either at a fixed temperature or at ambient temperature for $24 \mathrm{~h}$ (ref. ${ }^{15}$ ). Although ambient temperature incubation may facilitate the use of low-cost tests, further work is needed to identify when "ambient" is warm enough before this can be recommended for larger scale assessments of water quality. Thavarajah et al. review emerging synthetic biology approaches and suggest that these hold promise as rapid tests for a wide variety of water quality parameters and have the potential to overcome resistance to the use of genetically modified "whole cells" and the practical challenges this would entail ${ }^{16}$. The review focuses on the SDG priority parameters and indicates that sufficiently sensitive 
Table 1. Water quality results from selected nationally representative household surveys.

\begin{tabular}{|c|c|c|c|c|}
\hline Country & Survey & Year & $\begin{array}{l}\text { Proportion of } \\
\text { population with } \\
\text { E. coli detected } \\
\text { at point of } \\
\text { collection (\%) }\end{array}$ & $\begin{array}{l}\text { Proportion of } \\
\text { population } \\
\text { with } E \text {. coli } \\
\text { detected at } \\
\text { point of } \\
\text { use (\%) }\end{array}$ \\
\hline Bangladesh & MICS & 2019 & 40.3 & 81.9 \\
\hline Congo & MICS & 2014-15 & 48.1 & 77.7 \\
\hline Côte d'Ivoire & MICS & 2016 & 53.6 & 78.5 \\
\hline DPRK & MICS & 2017 & 23.5 & 36.6 \\
\hline DRC & MICS & 2018 & 59.6 & 74.6 \\
\hline Ecuador & ENEMDU & 2016 & 20.7 & N/A \\
\hline Ecuador & ENEMDU & 2019 & 26.5 & 32.0 \\
\hline Ethiopia & ESS-WQ & 2016 & 86.0 & 94.4 \\
\hline Gambia & MICS & 2018 & 45.3 & 73.2 \\
\hline Georgia & MICS & 2018 & 24.9 & 30.8 \\
\hline Ghana & MICS & 2016-17 & 48.3 & 76.1 \\
\hline Iraq & MICS & 2018 & 40.4 & 50.7 \\
\hline Kiribati & SDIS-MICS & 2017 & 85.1 & 91.1 \\
\hline Lao PDR & SIS-MICS & 2017 & 83.1 & 86.4 \\
\hline Lebanon & WQS & 2016 & 52.0 & 61.0 \\
\hline Lesotho & MICS & 2018 & 33.0 & 53.3 \\
\hline Madagascar & MICS & 2018 & 80.9 & 86.3 \\
\hline Mongolia & SISS-MICS & 2018 & 16.0 & 19.7 \\
\hline Nepal & MICS & 2014 & 71.1 & 82.2 \\
\hline Nigeria & MICS & $2016-17$ & 77.3 & 90.8 \\
\hline Paraguay & MICS & 2016 & 37.5 & 47.6 \\
\hline Philippines & APIS & 2017 & 51.9 & 67.3 \\
\hline Sierra Leone & MICS & 2017 & 89.5 & 96.9 \\
\hline Suriname & MICS & 2018 & 42.5 & 64.1 \\
\hline Togo & MICS & 2017 & 69.0 & 90.2 \\
\hline Tonga & MICS & 2019 & 70.1 & 78.1 \\
\hline Tunisia & MICS & 2018 & 20.4 & 28.9 \\
\hline Zimbabwe & MICS & 2018 & 59.0 & 83.8 \\
\hline \multicolumn{5}{|c|}{$\begin{array}{l}\text { Adapted from ref. }{ }^{7} \text {. } \\
\text { ALCS Afghanistan Living Conditions Survey, APIS Annual Poverty Indicator } \\
\text { Survey, DPRK Democratic People's Republic of Korea, DRC Democratic } \\
\text { Republic of Congo, ENEMDU Encuesta Nacional de Empleo, Desempleo y } \\
\text { Subempleo, ESS Ethiopia Socio-economic Survey, GLSS Ghana Living Standard } \\
\text { Study, Lao PDR Lao People's Democratic Republic, MICS Multiple Indicator } \\
\text { Cluster Survey, SIS Social Indicator Survey, SISS Social Indicator Sample Survey, } \\
\text { SDIS Social Development Indicator Survey, WQS Water Quality Survey. }\end{array}$} \\
\hline
\end{tabular}

methods are available for arsenic and fluoride but detection of low levels of faecal indicator bacteria remains a key challenge. Farnat et al. provide an example the use of flow cytometry for in-line testing ${ }^{17}$ which holds promise as a more dynamic and rapid approach than the use of culture-based methods for monitoring treatment effectiveness in piped systems and, critically, as a faster feedback loop to detect and address interruptions in water treatment. Flow cytometry remains a comparatively expensive approach but one of few that can rapidly differentiate viable and non-viable bacteria.

Progress toward safe drinking water for all provides a mirror against which to assess our collective efforts to address inequalities. Data gaps on SMDW services urgently need to be filled to guide efforts to improve drinking water services, to target those furthest behind and to track changes in services over time. This implies strengthening the key role of regulators in the oversight of drinking water service providers. Safe drinking water for all means providing reliable, affordable high-quality services in the most challenging contexts, including in the least developed countries, in small island states and in areas affected by conflict; reaching those left behind in all countries, including indigenous groups in high-income countries ${ }^{18}$; and focusing on gender and disabilitysensitive water services in public places such as schools and health care facilities. It means providing services that are affordable to the poorest households ${ }^{19}$ and delivering climate resilient drinking water services ${ }^{20}$ adapted to available water resources, ensuring demands for domestic water are met first ${ }^{21}$. Further work is also required to better understand the burden of disease $^{22}$ and economic impacts of inequalities in drinking water services levels. While the recent COVID-19 pandemic has undoubtedly heightened the challenges of maintaining and expanding safe water access, it has also served to underscore the importance of accessibility and availability of drinking water, to enable key preventative measures including social distancing and regular handwashing ${ }^{23}$.

\section{DATA AVAILABILITY}

All data are available from the WHO/UNICEF Joint Monitoring Programme website (washdata.org).

Robert Bain (iD) ${ }^{1 凶}$, Rick Johnston $\mathbb{D D}^{2}$ and Tom Slaymaker ${ }^{1}$ ${ }^{1}$ Division of Data, Planning, Analysis, and Monitoring, UNICEF, New York, NY, USA. ${ }^{2}$ Department of Environment, Climate Change and Health, WHO, Geneva, Switzerland. ${ }^{凶}$ email: rbain@unicef.org

Received: 12 August 2020; Accepted: 12 August 2020; Published online: 24 August 2020

\section{REFERENCES}

1. Bartram, J. Improving on haves and have-nots. Nature 452, 283-284 (2008).

2. WHO \& UNICEF. Progress on Drinking Water, Sanitation and Hygiene: 2017 Update and SDG Baselines (WHO \& UNICEF, Geneva, 2017).

3. WHO. Guidelines for Drinking-Water Quality 4th edn. (WHO, Geneva, 2017).

4. WHO \& UNICEF. Progress on Household Drinking Water, Sanitation and Hygiene 2000-2017: Special Focus on Inequalities (WHO \& UNICEF, New York, 2019).

5. Moreno, L. et al. Integrating water-quality analysis in national household surveys: water and sanitation sector learnings of Ecuador. npj Clean Water 3, 23 (2020).

6. Dorea, C. C. et al. Safely managed drinking water services in the Democratic People's Republic of Korea: findings from the 2017 Multiple Indicator Cluster Survey. npj Clean Water 3, 28 (2020).

7. WHO \& UNICEF. Integrating Water Quality Testing Into Household Surveys (WHO \& UNICEF, New York, 2020).

8. Jeandron, A., Cumming, O., Kapepula, L. \& Cousens, S. Predicting quality and quantity of water used by urban households based on tap water service. npj Clean Water 2, 23 (2019).

9. Marks, S. J. et al. Water supply and sanitation services in small towns in rural-urban transition zones: the case of Bushenyi-Ishaka Municipality, Uganda. npj Clean Water 3, 21 (2020).

10. Hubbard, S. C. et al. Household illness and associated water and sanitation factors in peri-urban Lusaka, Zambia, 2016-2017. npj Clean Water 3, 26 (2020).

11. Rawas, F., Bain, R. \& Kumpel, E. Comparing utility-reported hours of piped water supply to households' experiences. npj Clean Water 3, 6 (2020).

12. Nowicki, S., Koehler, J. \& Charles, K. J. Including water quality monitoring in rural water services: why safe water requires challenging the quantity versus quality dichotomy. npj Clean Water 3, 14 (2020).

13. String, G. et al. Efficacy of locally-available cleaning methods in removing biofilms from taps and surfaces of household water storage containers. npj Clean Water 3, 13 (2020).

14. Naser, A. M. et al. Associations of drinking rainwater with macro-mineral intake and cardiometabolic health: a pooled cohort analysis in Bangladesh, 2016-2019. npj Clean Water 3, 20 (2020). 
15. Brown, J., Bir, A. \& Bain, R. E. S. Novel methods for global water safety monitoring: comparative analysis of low-cost, field-ready E. coli assays. npj Clean Water 3, 9 (2020).

16. Thavarajah, W. et al. A primer on emerging field-deployable synthetic biology tools for global water quality monitoring. npj Clean Water 3, 18 (2020).

17. Farhat, N., Kim, L. H. \& Vrouwenvelder, J. S. Online characterization of bacterial processes in drinking water systems. npj Clean Water 3, 16 (2020).

18. Hall, N. L., Creamer, S., Anders, W., Slatyer, A. \& Hill, P. S. Water and health interlinkages of the sustainable development goals in remote Indigenous Australia. npj Clean Water 3, 10 (2020).

19. Hope, R. \& Ballon, P. Global water policy and local payment choices in rural Africa. npj Clean Water 2, 21 (2019).

20. MacAllister, D. J., MacDonald, A. M., Kebede, S., Godfrey, S. \& Calow, R. Comparative performance of rural water supplies during drought. Nat. Commun. 11, 1099 (2020).

21. Boretti, A. \& Rosa, L. Reassessing the projections of the World Water Development Report. npj Clean Water 2, 15 (2019).

22. Goddard, F. G. B., Chang, H. H., Clasen, T. F. \& Sarnat, J. A. Exposure measurement error and the characterization of child exposure to fecal contamination in drinking water. npj Clean Water 3, 19 (2020).

23. Howard, G. et al. COVID-19: urgent actions, critical reflections and future relevance of 'WaSH': lessons for the current and future pandemics. J. Water Sanit. Hyg. Dev. (2020).

\section{AUTHOR CONTRIBUTIONS}

R.B. drafted the first version of the editorial. All authors contributed to and revised subsequent versions.

\section{COMPETING INTERESTS}

The authors are members of the WHO/UNICEF Joint Monitoring Programme for Water Supply, Sanitation and Hygiene.

\section{ADDITIONAL INFORMATION}

Correspondence and requests for materials should be addressed to R.B.

Reprints and permission information is available at http://www.nature.com/ reprints

Publisher's note Springer Nature remains neutral with regard to jurisdictional claims in published maps and institutional affiliations.

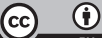

Open Access This article is licensed under a Creative Commons Attribution 4.0 International License, which permits use, sharing, adaptation, distribution and reproduction in any medium or format, as long as you give appropriate credit to the original author(s) and the source, provide a link to the Creative Commons license, and indicate if changes were made. The images or other third party material in this article are included in the article's Creative Commons license, unless indicated otherwise in a credit line to the material. If material is not included in the article's Creative Commons license and your intended use is not permitted by statutory regulation or exceeds the permitted use, you will need to obtain permission directly from the copyright holder. To view a copy of this license, visit http://creativecommons. org/licenses/by/4.0/.

(c) The Author(s) 2020 